\title{
Neuroanatomical Correlates of Implicit and Explicit Memory for Structurally Possible and Impossible Visual Objects
}

Anne Uecker, ${ }^{4,6}$ Eric M. Reiman, ${ }^{2,4}$ Daniel L. Schacter, ${ }^{3}$ Michael R. Polster, ${ }^{5}$ Lynn A. Cooper, ${ }^{1}$ Lang S. Yun, ${ }^{2}$ and Kewei Chen ${ }^{2}$

${ }^{1}$ Columbia University

New York, New York 10027

${ }^{2}$ Good Samaritan Regional Medical Center

Phoenix, Arizona 85006

${ }^{3}$ Harvard University

Cambridge, Massachusetts 02138

${ }^{4}$ University of Arizona

Tucson, Arizona 85724

${ }^{5}$ University of Victoria

Wellington, New Zealand

\section{Abstract}

Implicit memory refers to nonconscious retrieval of past experience demonstrated by facilitation in test performance on tasks that do not require intentional recollection of previous experiences. Explicit memory, in contrast, refers to the conscious retrieval of prior information, as demonstrated during standard recall and recognition tasks. In this experiment, positron emission tomographic (PET) measurements of regional cerebral blood flow (CBF), a marker of local neuronal activity, were used to identify and contrast brain regions that participate in the perception, implicit memory, and explicit memory for structurally possible and impossible visual objects. Ten CBF images were acquired in 16 normal women as they made possible/impossible and old/new recognition decisions about previously studied (old) and nonstudied (new) structurally possible and impossible objects. As reported previously, object decisions for familiar possible objects were associated with increased CBF in the vicinity of the left inferior temporal and fusiform gyri and

\footnotetext{
${ }^{6}$ Corresponding author.
}

recognition memory for familiar possible objects was associated with increased CBF in the vicinity of the right hippocampus. In this report, we provide more extensive analyses of the roles of the inferior temporal cortex, the hippocampus, the parahippocampus, and the pulvinar in encoding and retrieval operations. Additionally, patterns of CBF increases and decreases provide information regarding the neural structures involved in implicit and explicit memory.

\section{Introduction}

Implicit memory refers to nonconscious retrieval of past experience demonstrated by facilitation in task performance on tasks that do not require intentional retrieval of previous experiences, whereas explicit memory refers to the conscious recollection of past experience demonstrated during standard recall and recognition tasks (Graf and Schacter 1985; Schacter 1987). A variety of neuroanatomical systems are involved in different kinds of implicit memory, such as priming, skill learning, and habit acquisition, whereas explicit memory typically depends on the integrity of the medial temporal lobe (cf. Schacter and Tulving 1994; Squire 1994; Willingham 1997). For instance, many studies have demonstrated that amnesic patients

LEARNING \& MEMORY 4:337-355 @ 1997 by Cold Spring Harbor Laboratory Press ISSN1072-0502/97 \$5.00

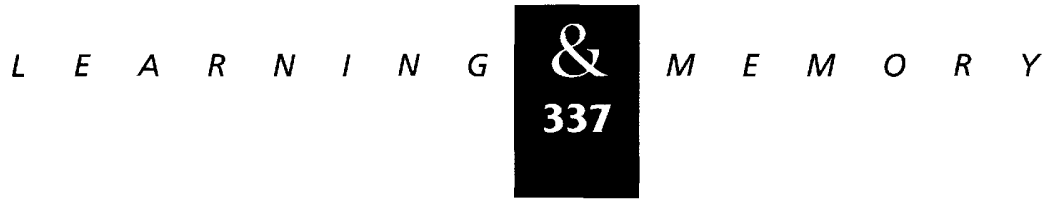


Uecker et al.

with damage to the medial temporal lobes show intact performance on a variety of implicit memory tasks (for reviews, see Richardson-Klavehn and Bjork 1988; Squire 1992; Graf and Masson 1993; Roediger and McDermott 1993; Schacter et al. 1993; Moscovitch 1994).

In this paper we examine the correlates of priming, perhaps the most frequently studied form of implicit memory. Priming occurs when study of a stimulus object produces a change in the ability to identify or make decisions about that object (Tulving and Schacter 1990). Whereas most studies of priming have used familiar words and pictures as target materials, Schacter, Cooper and their colleagues (Cooper et al. 1992; Schacter et al. 1990, 1991a,b, 1993; Schacter and Cooper 1993) have examined priming of two-dimensional line drawings depicting unfamiliar three-dimensional visual objects that are structurally possible (i.e., they could exist in three-dimensional form) or structurally impossible (surface or edge violations would prohibit their existence in three dimensions). Priming of these objects is observed when study of a possible or impossible object influences performance on a subsequent task in which subjects decide whether briefly flashed studied and nonstudied objects are possible or impossible. Explicit memory for the same objects is observed when subjects make accurate old/new recognition judgements about studied and nonstudied objects.

A series of experiments with the possible and impossible object set has demonstrated that priming is (1) observed for possible but not for impossible objects; (2) dependent on encoding the overall shape of the object; (3) minimally affected by semantic encoding operations that enhance explicit memory; (4) preserved in amnesic patients with medial temporal lobe damage and explicit memory deficits; and (5) insensitive to study-to-test changes in size and left/right reflection of objects that impair explicit memory (Cooper et al. 1992; Schacter et al. 1990, 1991a, 1993; Schacter and Cooper 1993). In each of these studies, explicit memory performance is also more accurate for possible than for impossible objects. On the basis of these and other previous results, Schacter and colleagues (Schacter et al. 1990) suggest that object decision priming might depend on a structural description system (Riddoch and Humphreys 1987) that represents information about the global structure of an object independently of its retinal size, left/right orientation, and explicit memory representation.
In this study, positron emission tomographic (PET) measurements of regional cerebral blood flow (CBF), a marker of local neuronal activity, were used to examine information processing of possible and impossible objects during implicit and explicit memory. In a previous report (Schacter et al. 1995), we focused primarily on two a priori hypotheses that concerned the processing of possible objects-one, that object decisions and object decision priming depend on a brain system, namely the inferior temporal lobe and fusiform gyrus region, which supports the global representation of visual objects (Schacter and Cooper 1993) and two, that explicit recognition memory depends on a brain system that includes the hippocampus and other medial temporal lobe structures (e.g., Squire and Zola-Morgan 1991; Squire et al. 1992). In this report, we more fully elaborate on the blood flow changes that occurred in regions outside of the inferior and medial temporal lobe regions in response to the processing of possible objects, and we more fully elaborate on all of the blood flow changes that occurred in response to the processing of impossible objects. Additional post-hoc data analyses explore the role of object, task, and hemisphere effects in the inferior temporal cortex, hippocampus, parahippocampus, and thalamus in the encoding and retrieval of structurally possible and impossible objects.

\section{Materials and Methods}

\section{SUBJECTS}

Sixteen right-handed, healthy, unmedicated female volunteers between the ages of 18 and 30 were screened using psychiatric and medical histories, a neurological examination, the Structured Clinical Interview for DSM-III-R-Non-Patient Version (SCID-NP), the Edinburgh Handedness Inventory, and a complete neurological exam. Each participant was studied under guidelines approved by the human subjects committee at Good Samaritan Regional Medical Center (Phoenix, AZ.).

\section{PROCEDURE}

MAGNETIC RESONANCE IMAGING

Before the PET session, magnetic resonance imaging (MRI) was performed on each subject us-

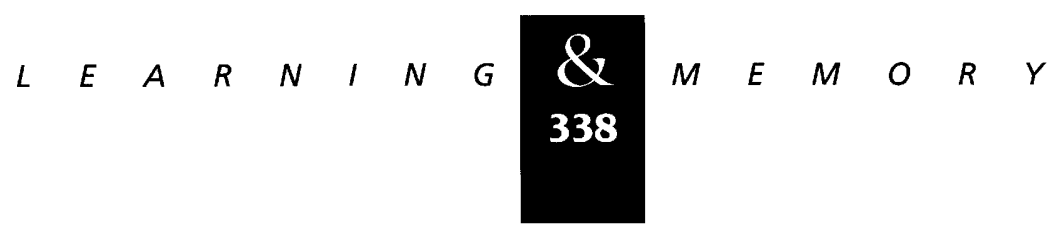


ing the 1.5 Tesla Signa system (General Electric, Milwaukee, WI). T1-weighted, sagittal and coronal images of the brain were used to minimize tilt and optimize axial sampling in the PET scanner. A T1weighted, three-dimensional, Volume Spoiled Recalled Acquisition in the Steady State pulse sequence (SPGR, TE $=5 \mathrm{msec}, \mathrm{TR}=33 \mathrm{msec}$, angle $=30^{\circ}, \mathrm{NEX}=1, \mathrm{FOV}=24 \mathrm{~cm}$, imaging matrix $=256 \times 192$ ) was used to acquire 128 contiguous, $1.5-\mathrm{mm}$-thick, horizontal slices of the brain to rule out gross anatomical abnormalities and facilitate comparisons between brain function and structure.

PET

Subject preparation for PET included the insertion of a catheter in the left antecubital vein to permit tracer administration, use of a fast hardening foam mold to immobilize the head, and the performance of a transmission scan using a germanium-68-gallium-68 ring source to correct subsequent emission images for radiation attenuation. During each scan, the subject rested quietly in the supine position.

In total, 10 31-slice PET images of regional CBF were obtained in each subject during two baseline and eight memory conditions using the ECAT 951/ 31 scanner (Siemens, Knoxville, TN), $40 \mathrm{mCi}$ intravenous injections of the radio tracer $15-\mathrm{O}$ water, 60-sec scans, and an interval of 10-15 min between scans. During each of the 10 scans, there were 20 stimulus presentations consisting of (1) a 250-msec cross-hair fixation point; (2) a blank 100-msec scan interval; (3) an object at central fixation for 50msec followed by a key-press response; and (4) a 2500-msec intertrial delay. The radio tracer was administered at predetermined times shortly after the onset of the stimuli.

\section{BEHAVIORAL PILOT STUDIES}

In previous behavioral studies, possible and impossible objects were intermixed in a random sequence during object decision and recognition tests, which were performed independently (cf. Schacter et al. 1990). To accommodate the constraints of PET neuroimaging, we segregated the object types into blocks that corresponded to individual 1-min scans for each of the memory tasks. Several behavioral "dry runs" established that these revised object decision and recognition tasks incorporated the standard behavioral signatures of each task (i.e., priming for possible but not impossible objects, and more accurate recognition for possible than impossible objects). Pilot testing also excluded the possibility of learning effects within each block.

BEHAVIORAL TESTING DURING PET NEUROIMAGING

We used a set of 60 possible and 60 impossible objects that had been developed in previous research (e.g., Schacter et al. 1991a). All of the possible and impossible objects were divided into three equal sets. During the experiment, the first set of each object type was presented four timesonce during a baseline condition of passive looking, once during the study task, once during the object decision task, and once during the recognition task. This object set comprised the "old" or "studied" items. The second set of each object type comprised the "new" or "nonstudied" items during the object decision test, and did not appear at any other time in the experiment. The third set of each object type comprised the new or nonstudied items during recognition task. These also did not appear at any other time in the experiment. The experimental protocol and examples of possible and impossible objects are shown in Table 1.

Each subject was tested in each memory condition and was exposed to all of the visual stimuli. Although the memory tasks themselves were always presented in the same order, the order of the presentation of the sets of objects (studied possible, nonstudied possible, studied impossible, nonstudied impossible) was counterbalanced across subjects, fully for 12 subjects and partially for four others. Behavioral conditions for this experiment were conducted as follows.

1. Passive viewing. Subjects were first shown individual objects for $50 \mathrm{msec}$ per object and they were required to press one of two buttons after the object disappeared. Subjects were presented two sets of objects (one containing only possible objects and one containing only impossible objects) $\sim 10 \mathrm{~min}$ apart. This task served as the baseline measure in the PET procedure.

2. Tool/support study task. To present objects for sufficient time to ensure adequate encoding, the same 40 objects (20 possible and 20 impossible) that were presented in the baseline phase

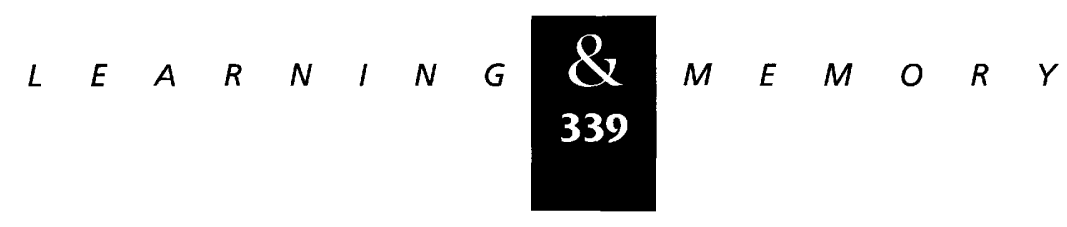


Uecker et al.

Table 1: Experimental protocol, comparisons, cognitive operations, and examples of possible and impossible objects

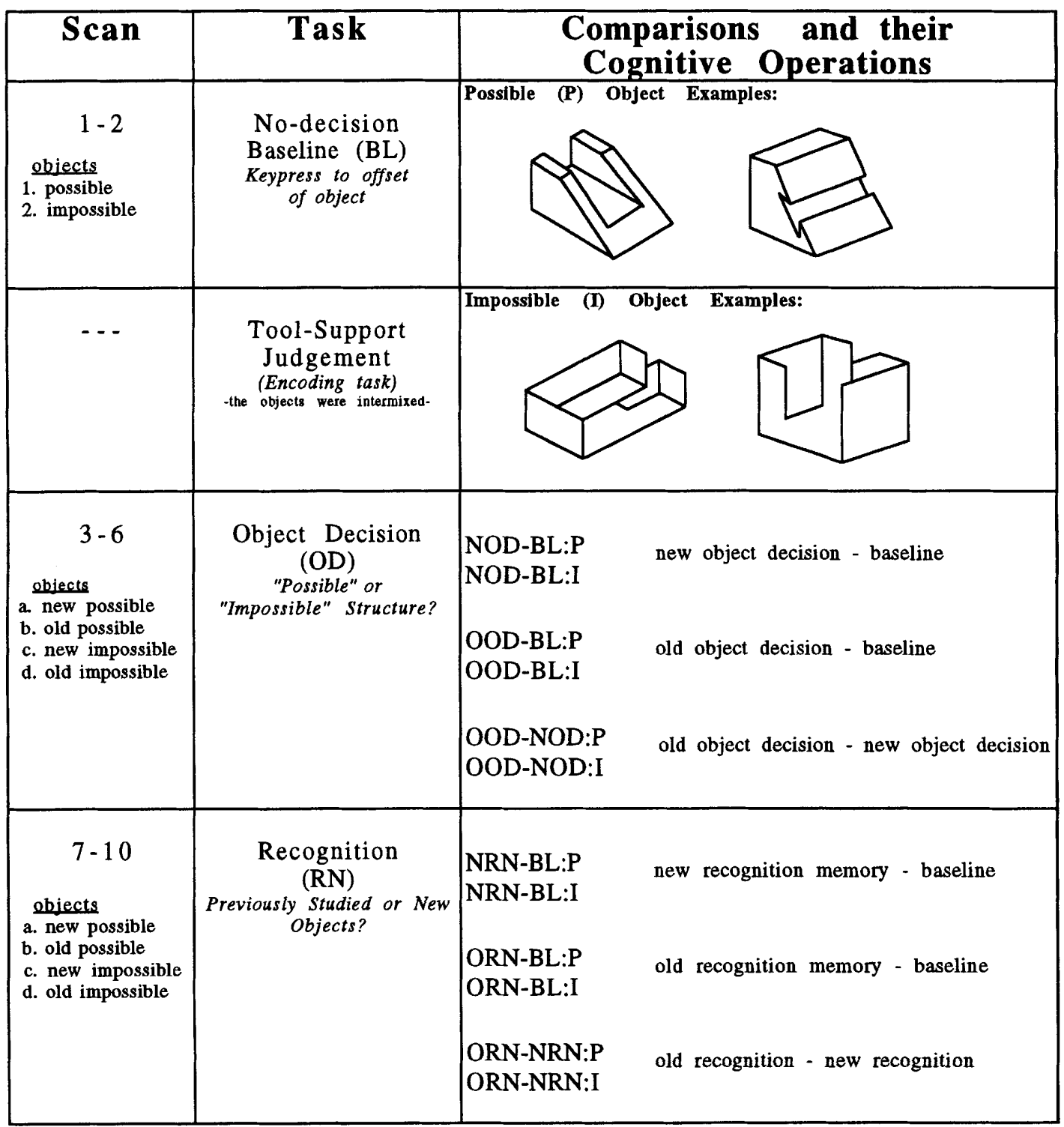

of the experiment were presented again in random sequence for $5 \mathrm{sec}$ each. As in Schacter and Cooper (1993), subjects were asked to decide whether each object could be best used as a tool or as support. After completing one cycle through this set of 40 objects, the order of presentation was altered and the same set was presented again. No PET data were collected during this phase of the experiment.

3. Object decision task. In the third phase of the experiment, subjects were engaged in an object decision task in which they were required to decide whether a two-dimensional drawing of a novel object could exist in the three-dimensional world. Subjects were first given instructions concerning how to perform the object decision task and shown examples of possible and impossible objects. The presentation conditions for these objects were identical to those of the passive viewing (baseline) phase of the experiment. That is, objects were presented in sets of 20 (all of which were either possible or impossible), and each object was presented for 50 msec. As in the baseline condition, two keys

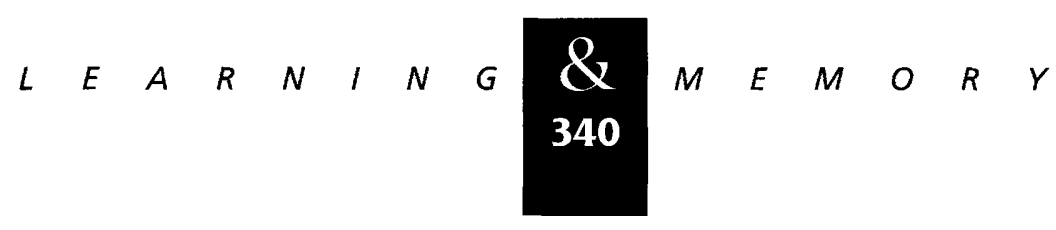


were used to record subjects' responses-one key was pressed if subjects thought the object was possible and the other if they thought it was impossible. Four different sets of objects were presented-old possible objects, old impossible objects, new possible objects, and new impossible objects. Approximately $10 \mathrm{~min}$ elapsed between presentation of each set of items.

4. Recognition/explicit memory. The final phase of the experiment required subjects to decide whether or not an object had been presented before during the experiment. The presentation conditions for these objects were identical to those during baseline and object decision. In this case, however, subjects were asked to press one button if they had seen the item before and another button if they had not. Once again four sets of objects were presented-old possible, old impossible, new possible, and new impossible.

\section{DATA ANALYSIS}

PET images were reconstructed with an inplane resolution of $\sim 10 \mathrm{~mm}$ full width at half maximum (FWHM) and a slice thickness of $-5 \mathrm{~mm}$ FWHM. For data analysis, a Gaussian blur yielded an in-plane resolution of $\sim 20 \mathrm{~mm}$ FWHM and a slice thickness of $\sim 10 \mathrm{~mm}$ FWHM. Automated algorithms were used to align each subject's sequential PET images (Mintun and Lee 1991), transform her PET images into the standard spatial coordinates of a brain atlas (Talairach and Tournoux 1988), investigate regional blood flow increases and decreases during object decision and recognition memory using statistical parametric mapping (SPM; Friston et al. 1990), investigate differences in the blood flow in inferior temporal, hippocampus, and dorsolateral prefrontal regions between the left versus the right hemisphere. To reduce type 1 errors, a critical $t$-value of 2.58 ( $P<0.005$ uncorrected for multiple comparisons) was used to characterize significant increases in regional blood flow; a critical $t$-value of $1.65(P<0.05$, uncorrected for multiple comparisons) was used post hoc if the region was implicated in the comparison of interest or in a specific hemisphere. One-tailed $t$-values are used to look at increases or decreases in a single comparison, not cumulative increases and decreases. An empirical evaluation of PET's sensitivity in detecting true signals and distinguish- ing them from false signals and noise has been provided by Reiman and colleagues (1997).

Other region-of-interest (ROI) post-hoc analyses involved the extraction of raw PET counts using two different methods. The first region of interest approach extracted PET counts from the hippocampus, parahippocampus, anterior thalamus, and posterior thalamus (pulvinar) using the Talairach and Tournoux (1988) coordinate points for each of these regions (see Table 2). These values were evaluated with an ANOVA to further explore main effects and interactions between tasks (object decision and recognition memory), object types (possible vs. impossible objects), and object familiarity (studied versus nonstudied objects).

The second ROI approach involved only the hippocampus. The hippocampus in transaxial section was manually defined using the image processing software MIDAS (Tsui 1995). Accurate boundary information was obtained by the simultaneous display and definition of the hippocampus in the sagittal plane. After ROI definition, each subjects' MRI was aligned to each of her unblurred PET scans by a surface matching algorithm that estimated the accuracy of its coregistration by providing a residual that measured the distance between the surface of the two images. Raw PET count statistics from the hippocampus were extracted and subsequently normalized to the raw PET counts of the whole brain. The hippocampus on one coregistered PET image is shown in Figure 1.

\section{Results}

\section{TASK PERFORMANCE}

To investigate priming effects, the proportions of correct possible/impossible object decisions for previously studied (old) objects (possible $=0.67$; impossible $=0.63$ ) were compared with the corresponding proportions of correct object decisions for not previously studied (new) objects (possible $=0.56 ;$ impossible $=0.58$ ). As demonstrated in previous experiments, the old possible objects were associated with a significant object-decision priming effect (i.e., an increase in the proportion of possible decisions for studied possible objects compared with nonstudied possible objects), $t(15)=3.01, P<0.005$; the old impossible objects were not associated with a significant object-decision priming effect, $t(15)<1$.

For recognition memory, we compared the

$$
\begin{array}{llllllllllllllll}
\hline & E & A & R & N & I & N & G & \begin{array}{l}
\text { \& } \\
341
\end{array} & M & E & M & O & R & Y
\end{array}
$$


Uecker et al.

Table 2: Coordinate points used for the extraction of PET counts from the hippocampus, parahippocampus, and anterior and posterior thalamus regions in Talairach space

\begin{tabular}{|c|c|c|c|c|c|c|c|c|}
\hline \multirow[t]{2}{*}{$\begin{array}{c}z \\
\text { level }\end{array}$} & \multicolumn{2}{|c|}{ HIPPOCAMPUS } & \multicolumn{2}{|c|}{$\begin{array}{c}\text { PARA } \\
\text { HIPPOCAMPUS }\end{array}$} & \multicolumn{2}{|c|}{$\begin{array}{l}\text { ANTERIOR } \\
\text { THALAMUS }\end{array}$} & \multicolumn{2}{|c|}{ PULVINAR } \\
\hline & $\underline{x}$ & $y$ & $\underline{x}$ & $y$ & $\underline{\mathbf{x}}$ & $\mathbf{y}$ & $\underline{x}$ & y \\
\hline \multirow{3}{*}{-20} & $30-25$ & $-10-(-15)$ & $30-25$ & $-15-(-20)$ & & & & \\
\hline & $25-20$ & $-10-(-15)$ & $30-25$ & $-20-(-25)$ & & & & \\
\hline & & & $35-30$ & $-20-(-25)$ & & & & \\
\hline \multirow{4}{*}{-16} & $30-25$ & $-10-(-15)$ & $30-25$ & $-20-(-25)$ & & & & \\
\hline & $25-20$ & $-10-(-15)$ & $30-25$ & $-25-(-30)$ & & & & \\
\hline & $35-30$ & $-15-(-20)$ & & & & & & \\
\hline & $30-25$ & $-15-(-20)$ & & & & & & \\
\hline \multirow{4}{*}{-12} & $30-25$ & $-10-(-15)$ & $30-25$ & $-25-(-30)$ & & & & \\
\hline & $35-30$ & $-15-(-20)$ & $30-25$ & $-30-(-35)$ & & & & \\
\hline & $30-25$ & $-15-(-20)$ & & & & & & \\
\hline & $30-25$ & $-25-(-30)$ & & & & & & \\
\hline \multirow{3}{*}{-8} & $30-25$ & $-20-(-25)$ & $25-20$ & $-30-(-35)$ & & & & \\
\hline & $35-30$ & $-25-(-30)$ & $25-20$ & $-35-(-40)$ & & & & \\
\hline & $30-25$ & $-25-(-30)$ & & & & & & \\
\hline \multirow[t]{2}{*}{-4} & $30-25$ & $-30-(-35)$ & $25-20$ & $-40-(-45)$ & & & & \\
\hline & $25-20$ & $-30-(-35)$ & & & & & & \\
\hline \multirow[t]{2}{*}{0} & $30-25$ & $-30-(-35)$ & $20-15$ & $-35-(-40)$ & & & & \\
\hline & $30-25$ & $-35-(-40)$ & & & & & & \\
\hline \multirow[t]{3}{*}{4} & $30-25$ & $-35-(-40)$ & $30-25$ & $-45-(-50)$ & $15-10$ & $-10-(-15)$ & $25-20$ & $-25-(-30)$ \\
\hline & $25-20$ & $-35-(-40)$ & $25-20$ & $-45-(-50)$ & $10-5$ & $-10-(-15)$ & $20-15$ & $-25-(-30)$ \\
\hline & & & $20-15$ & $-42-(47)$ & $10-5$ & $-15-(-20)$ & $15-10$ & $-25-(-30)$ \\
\hline \multirow{4}{*}{8} & & & & & $10-5$ & $-5-(-10)$ & $20-15$ & $-20-(-25)$ \\
\hline & & & & & $15-10$ & $-10-(-15)$ & $10-5$ & $-20-(-25)$ \\
\hline & & & & & $10-5$ & $-10-(-15)$ & $20-15$ & $-25-(-30)$ \\
\hline & & & & & & & $15-10$ & $-25-(-30)$ \\
\hline \multirow{4}{*}{12} & & & & & & $-5-(-10)$ & $20-15$ & $-22-(-25)$ \\
\hline & & & & & $10-5$ & $-10-(-15)$ & $20-15$ & $-25-(-30)$ \\
\hline & & & & & $20-15$ & $-15-(-20)$ & $15-10$ & $-25-(-30)$ \\
\hline & & & & & $15-10$ & $-15-(-20)$ & & \\
\hline \multirow[t]{3}{*}{16} & & & & & $15-10$ & $-10-(-15)$ & $13-18$ & $-22-(-26)$ \\
\hline & & & & & $10-5$ & $-10-(-15)$ & & \\
\hline & & & & & $15-10$ & $-15-(-20)$ & & \\
\hline
\end{tabular}

proportion of old responses with previously presented objects (i.e., the hit rate; for possible ob- jects $=0.82$; for impossible objects $=0.68$ ) to the proportion of old responses to new objects (i.e.,

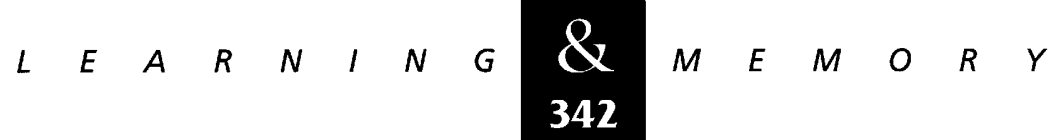




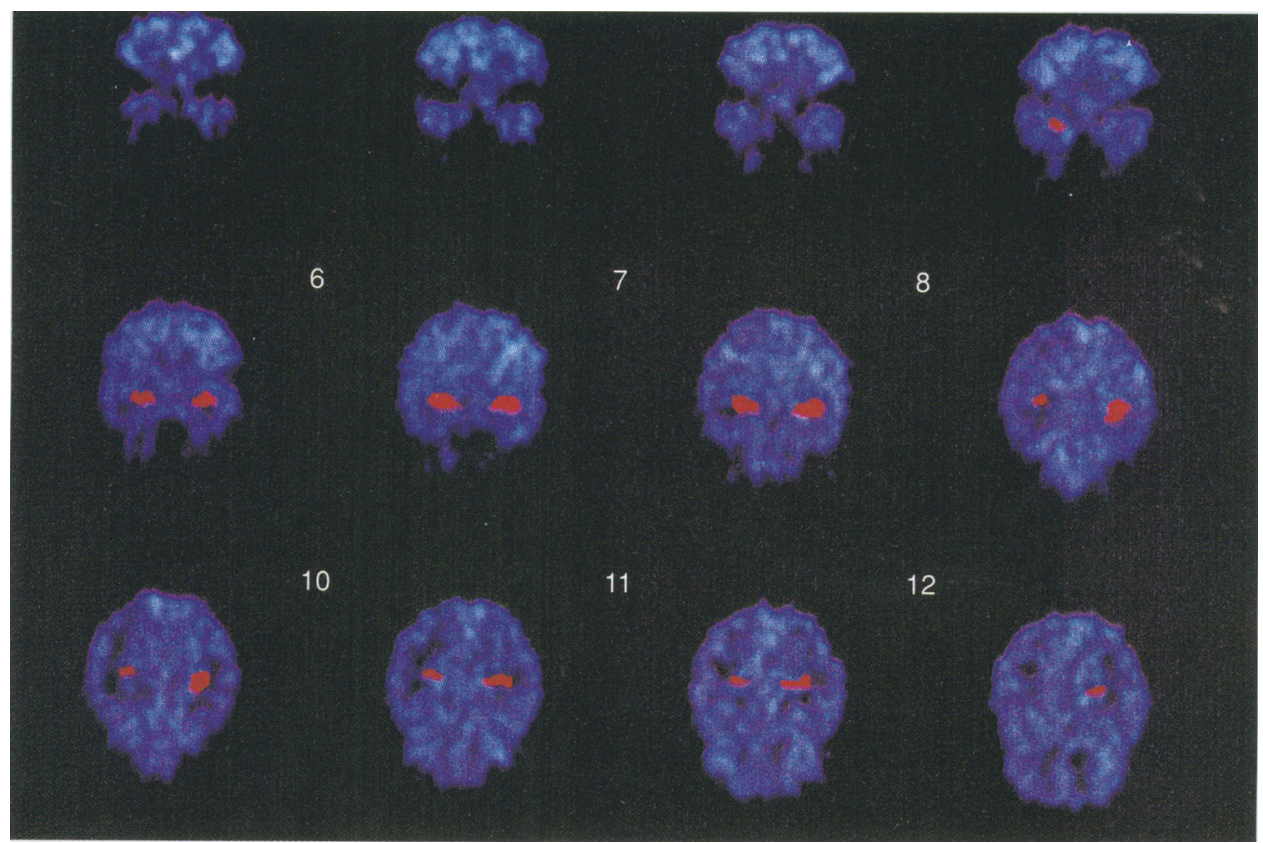

Figure 1: Each subject's hippocampal formation (shown in red) was defined on her respective MRI image and then coregistered to each of her PET images. The hippocampus of one subject after coregistration to a transaxial ventral-todorsal oriented PET image is illustrated. The left side of the image corresponds to the left hemisphere and the face is pointed down.

the false alarm rate; for possible objects $=0.33$; for impossible objects $=0.36$ ). As demonstrated in previous experiments, the corrected recognition score (hit rate - false alarm rate) for possible objects $(0.49)$ was significantly higher than corrected recognition score for impossible objects $(0.32)$, $t(15)=4.58, P<0.001$. The results for both the object-decision and recognition memory tasks are illustrated in Figure 2.

\section{POSITRON EMISSION TOMOGRPHY}

\section{ABBREVIATIONS}

Throughout the remainder of the text, the following abbreviations serve to identify combinations of task and stimulus conditions used in statistical comparisons and relevant subtractions: (OD) object decision task; $(\mathrm{RN})$ recognition memory task; (BL) no-decision baseline task; $(\mathrm{O})$ old or previously studied; $(\mathrm{N})$ new or nonstudied; $(\mathrm{P})$ possible object; (I) impossible object. Therefore, the acronym OOD-NOD:P should be read "old object decision minus new object decision on possible objects," and it designates subtraction of the regional activation associated with performance for one object decision condition compared with another object decision condition. At a more theoretical level, this label refers to regional CBF attributable to priming of possible/impossible decisions concerning previously studied possible objects. A list of the key task acronyms can be found in Table 1.

\section{OVERVIEW}

As reported recently (Schacter et al. 1995), object decisions about possible objects were associated with significant CBF changes in the vicinity of the inferior temporal and adjacent fusiform gyri and recognition decisions about possible and impossible objects were associated with significant $\mathrm{CBF}$ increases in the vicinity of the hippocampal formation. These findings are described briefly under the subheading Hypothesis-Testing.

Hypothesis-Generating data analyses examined the role of the inferior temporal and adjacent fusiform gyri and the hippocampus and parahippocampus region in encoding and retrieval processes during implicit and explicit memory, as well increases and decreases in CBF that occurred in several other brain regions, namely the frontal cortex, 


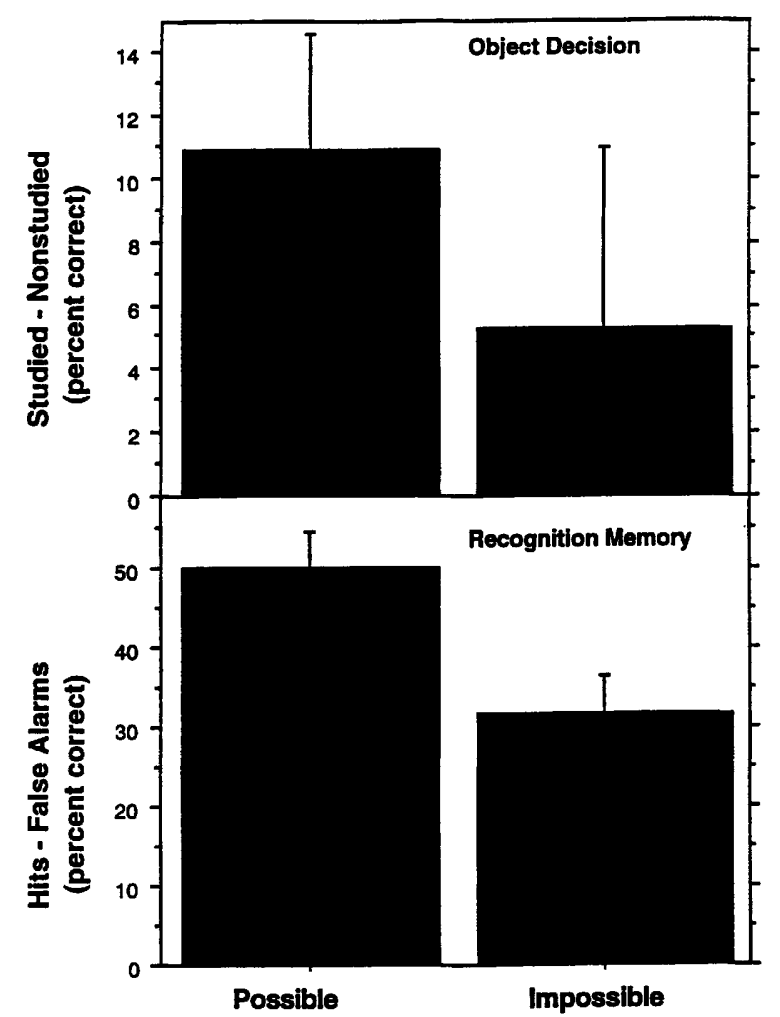

Figure 2: "Old" minus "new" performance for possible and impossible objects in object decision and recognition memory.

the pulvinar region of the thalamus, the primary and secondary occipital regions, the cingulate gyrus, basal ganglia, the insula and claustrum, the precuneus region, the temporoparietal areas, and the cerebellum (see Table 3 for a listing of regions, specific locations in Talairach space, and maximal $t$-values). Brain imaging data traditionally invite speculation about the commission of type 1 errors (i.e., inappropriate rejection of the null hypothesis). Although the likelihood of this statistical error is reduced by the bilateral nature and reproducibility of most of the blood flow changes, these findings are best viewed as provisional evidence of candidate regions that underlie implicit and explicit memory performance.

\section{HYPOTHESIS TESTING}

INFERIOR TEMPORAL AND FUSIFORM GYRUS

Blood flow increases in inferior temporal regions 21 and 37, the fusiform gyrus, and the posterior sector of the middle temporal gyrus oc- curred during object decisions for possible objects. The increases were bilateral for OOD-BL:P, on the right for NOD-BL:P, and on the left for OODNOD:P (Schacter et al. 1995).

HIPPOCAMPUS AND PARAHIPPOCAMPAL GYRUS

Blood flow increases in the hippocampus and parahippocampal gyrus region occurred during both object decision and recognition memory, as well as in response to both object types. Blood flow increases were bilateral in ORN-BL:P, on the left in NRN-BL:P, and on the right in ORN-NRN:P. Blood flow increases in the left hippocampal region occurred during ORN-BL:I and NRN-BL:I, as well during object decisions for impossible objects (OOD-BL:I and NOD-BL:I; Schacter et al. 1995).

\section{HYPOTHESIS GENERATING}

INFERIOR TEMPORAL AND FUSIFORM GYRUS

Post hoc analyses of the data from the inferior temporal and fusiform gyrus region that resulted from SPM revealed several effects. (1) CBF increases in NOD-BL:P and OOD-NOD:P were significantly greater in the right and left inferior temporal regions, respectively, than in these same regions in the opposite hemisphere; (2) right inferior temporal and fusiform increases were greater during object decisions for nonstudied possible as contrasted to nonstudied impossible objects $(P<$ 0.05 ), and left inferior temporal and fusiform were greater during object decision priming (OODNOD) for possible objects as contrasted to impossible objects; and (3) bilateral increases in the inferior temporal region occurred when object decision and recognition memory were contrasted directly (OOD-ORN:P; $P<0.05$ ).

\section{HIPPOCAMPUS AND PARAHIPPOCAMPAL GYRUS}

Post hoc analyses of the data from the hippocampus and parahippocampal region that resulted from SPM revealed several additional effects. (1) Blood flow increases were significantly greater in the right hippocampal region during ORN-BL:P, and in the left hemisphere in response to all of the tasks that involved impossible objects; (2) the blood flow increase was significantly greater in the region of the right hippocampus for possible as

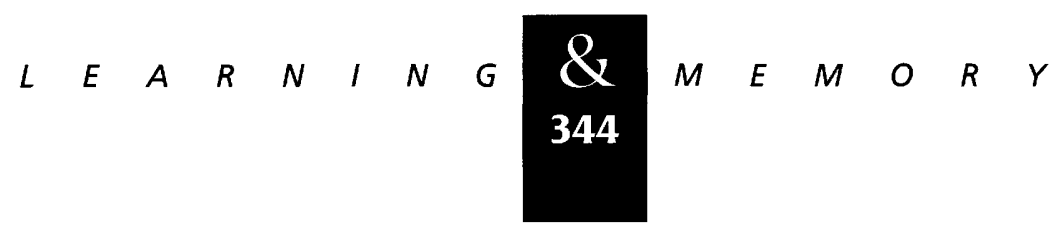


Table 3: Maximal t-values and their locations in Talairach space

\begin{tabular}{|c|c|c|c|c|c|c|c|c|c|c|c|c|c|c|c|c|c|c|c|}
\hline \multicolumn{10}{|c|}{ SOMATOSENSORY AND MOTOR } & \multicolumn{10}{|c|}{ CINGULATE CORTEX } \\
\hline \multirow[t]{2}{*}{ OOD:P } & -34 & -6 & 28 & 2.97 & ORN:P & -42 & 14 & 28 & 3.53 & OOD:P & 0 & -60 & $16 \%$ & 31: & ORN:P & 16 & 2 & 28 & 4.29 \\
\hline & & & & & & & & & & & 0 & -64 & 12 & 285 & & -14 & 6 & 28 & 2.96 \\
\hline \multirow[t]{2}{*}{ NOD:P } & -38 & -2 & 24 & 3.73 & NRN:P & -48 & -6 & 36 & 3.89 & NOD:P & & & & & NRN:P & -10 & 18 & 20 & 2.78 \\
\hline & & & & & & & & & & & 4 & -10 & 32 & 263 & & & & & \\
\hline \multirow[t]{2}{*}{ OOD:I } & -38 & -2 & 24 & 4.7 & ORN:I & -50 & 2 & 32 & 4.5 & OOD:I & & & & & ORN:I & -20 & -14 & 32 & 3.9 \\
\hline & & & & & & & & & & & & & & & & 28 & -12 & 28 & 2.88 \\
\hline \multirow[t]{2}{*}{ NOD:I } & -38 & -2 & 24 & 4.8 & NRN:I & -42 & -2 & 24 & 3.63 & NOD:I & & & & & NRN:I & -14 & 32 & 12 & 4.07 \\
\hline & 38 & -12 & 24 & 3.44 & & & & & & & & & & & & 16 & 14 & 28 & 2.81 \\
\hline \multicolumn{10}{|c|}{ DORSOLATERAL PREFRONTAL CORTEX } & \multicolumn{10}{|c|}{ LENTIFORM AND CAUDATE NUCLEUS } \\
\hline \multirow[t]{2}{*}{ OOD:P } & -40 & 26 & 16 & 4.14 & ORN:P & -24 & 32 & 16 & 5.02 & OOD:P & & & & & ORN:P & -20 & 2 & 20 & 4.37 \\
\hline & 32 & 22 & 20 & 3.4 & & 34 & 22 & 16 & 4.8 & & 18 & 8 & 20 & 3.2 & & 24 & 10 & 12 & 3.62 \\
\hline \multirow[t]{2}{*}{ NOD:P } & -38 & 26 & 16 & 3.63 & NRN:P & & & & & NOD:P & & & & & NRN:P & -22 & -30 & 20 & 3.95 \\
\hline & 30 & 20 & 20 & 4.26 & & 30 & 24 & 16 & 3.7 & & & & & & & 22 & -32 & 16 & 2.63 \\
\hline \multirow[t]{2}{*}{ OOD:1 } & -36 & 30 & 16 & 3.79 & ORN:I & -24 & 38 & 16 & 5.04 & OOD:I & -16 & 4 & 20 & 2.81 & ORN:I & -18 & -36 & 16 & 3.77 \\
\hline & 36 & 20 & 20 & 4.39 & & 32 & 18 & 20 & 5.29 & & 16 & 28 & 4 & 3.09 & & 22 & -36 & 20 & 4.1 \\
\hline \multirow[t]{2}{*}{ NOD:I } & -26 & 36 & 16 & 4.17 & NRN:I & -24 & 44 & 12 & 4.04 & NOD:I & -14 & 2 & 20 & 3.09 & NRN:I & -22 & -38 & 12 & 5.22 \\
\hline & 34 & 22 & 20 & 4 & & 24 & 36 & 8 & 5.22 & & 26 & -12 & 8 & 3.27 & & 16 & -32 & 20 & 4.21 \\
\hline ORBITO & FROI & NTAL & COR & RTEX & & & & & & INSULAR & $\mathrm{COF}$ & RTEX & & & & & & & \\
\hline OOD:P & -14 & 28 & -24 & 2.9 & ORN:P & -28 & 28 & 0 & 4.42 & OOD:P & -40 & 16 & 8 & 4.24 & ORN:P & -30 & 2 & 16 & 3.66 \\
\hline & & & & & & 18 & 34 & -12 & 3.44 & & 30 & 18 & 4 & 2.95 & & 28 & 8 & 16 & 4.48 \\
\hline NOD:P & -14 & 38 & -16 & 2.95 & NRN:P & -20 & 42 & 0 & 2.99 & NOD:P & -36 & 14 & 8 & 4.01 & NRN:P & & & & \\
\hline & 22 & 28 & -4 & 3.4 & & 20 & 24 & -4 & 3.16 & & 30 & 18 & 4 & 3.77 & & 32 & 8 & 16 & 3.82 \\
\hline OOD:I & -38 & 24 & -4 & 3.53 & ORN:I & -20 & 40 & -4 & 3.82 & OOD:I & -34 & 16 & 4 & 3.88 & ORN:I & -34 & -4 & 20 & 3.64 \\
\hline & 26 & 34 & -12 & 3.03 & & 18 & 28 & -4 & 3.37 & & & & & & & 30 & 2 & 16 & 4.17 \\
\hline NOD:I & -28 & 26 & -4 & 2.98 & NRN:I & -24 & 42 & -4 & 4.64 & NOD:I & -34 & 14 & 8 & 3.73 & NRN:I & -30 & 20 & 4 & 3.19 \\
\hline & 20 & 24 & -8 & 2.78 & & 24 & 44 & -4 & 3.33 & & 30 & 2 & 16 & 4.15 & & 32 & -4 & 20 & 3.96 \\
\hline POSTE & रIOR & THAL & AMU & & & & & & & PRECUN & EUS & REGI & ON & & & & & & \\
\hline OOD:P & & & & & ORN:P & & & & & OOD:P & -4 & -58 & 36 & 429 & ORN:P & -2 & -46 & 36 & 48 \\
\hline & & & & & & & & & & & 2 & -56 & 24 & 42 & & 0 & -58 & 36 & 543 \\
\hline NOD:P & & & & & NRN:P & & & & & NOD:P & -8 & -58 & 32 & 466 & NRN:P & -10 & -54 & 36 & 481 \\
\hline & & & & & & -6 & -30 & 8 & 2.76 & & 0 & -48 & 36 & 458 & & 2 & -60 & 36 & 494 \\
\hline OOD:I & & & & & ORN:I & -22 & -20 & 16 & 3.94 & OOD:I & -4 & -58 & 36 & 45 & ORN:I & -2 & -40 & 36 & 402 \\
\hline & 20 & -20 & 16 & 2.6 & & 20 & -20 & 16 & 4.67 & & 2 & -58 & 40 & 458 & & 6 & -62 & 28 & 3 86 \\
\hline NOD:I & & & & & NRN:I & -22 & -26 & 12 & 3.21 & NOD:I & -4 & -54 & 24 & 459 & NRN:I & -6 & 62 & 28 & 532 \\
\hline & 18 & -18 & 12 & 2.98 & & 22 & -18 & 16 & 3.59 & & 2 & -44 & 32 & 528 & & -10 & -60 & 36 & 483 \\
\hline MEDIA & PRE & FROA & NTAL & & & & & & & TEMPOR & OPA & RIET & $A L C$ & ORTE) & & & & & \\
\hline OOD:P & -8 & 48 & 20 & 31 & ORN:P & & & & & OOD:P & -40 & -48 & 12 & 395 & ORN:P & -40 & -60 & 83 & 44: \\
\hline & 4 & 44 & 20 & 328 & & & & & & & 44 & -54 & 8 & 476 & & 44 & -56 & 8 & 821 \\
\hline NOD:P & & & & & NRN:P & & & & & NOD:P & -36 & -58 & 8 & 424 & NRN:P & -42 & -48 & 8 & 4,3 \\
\hline & & & & & & & & & & & 40 & -60 & 8 & 386 & & 40 & -56 & 16 & 4,5 \\
\hline OOD:I & & & & & ORN:I & & & & & OOD:I & -48 & -58 & 12 & 304 & ORN:I & -50 & -30 & 12 & 208 \\
\hline & & & & & & & & & & & 40 & -56 & 8 & 553 & & 46 & -50 & 4 & 543 \\
\hline NOD:I & & & & & NRN:I & & & & & NOD:I & -50 & -32 & 12 & 296 & NRN:I & -44 & -54 & 8 & 454 \\
\hline & & & & & & & & & & & 40 & -56 & 4 & 483 & & 40 & -56 & 8 & 509 \\
\hline OCCIPI & L & OR & EX & & & & & & & CEREE & LLUI & & & & & & & & \\
\hline OOD:P & & & & & ORN:P & -10 & -64 & 28 & 45 & OOD:P & -14 & -66 & -8 & 28 & ORN:P & -12 & -76 & -12 & 319 \\
\hline & & & & & & 0 & -74 & -4 & 30 & & 14 & -58 & -20 & 318 & & 14 & -66 & -20 & 431 \\
\hline NOD:P & -26 & -68 & & 32 & NRN:P & -6 & -56 & 32 & 448 & NOD:P & -4 & -52 & -8 & 27 & NRN:P & -12 & -58 & -12 & 2,58 \\
\hline & & & & & & 20 & -68 & 16 & 282 & & 14 & -66 & -16 & 367 & & 34 & -42 & -24 & 291 \\
\hline OOD:I & -12 & -68 & & 325 & ORN:I & -6 & -56 & 32 & 44. & OOD:I & -8 & -68 & -8 & 301 & ORN:I & -18 & -58 & -16 & 349 \\
\hline & 16 & -68 & & 338 & & 20 & -68 & 16 & 282 & & 10 & -66 & -16 & (8) & & 12 & -62 & -16 & 36 \\
\hline NOD:I & & & & & NRN:I & -6 & -70 & 8 & 32 & NOD:I & -2 & -72 & -8 & 3.53 & NRN:I & -10 & -60 & -16 & 3,37 \\
\hline & & & & & & 2 & -72 & -4 & 284 & & 6 & -68 & -12 & 405 & & 10 & -66 & 12 & 4,4 \\
\hline
\end{tabular}

Refer to Table 1 for a listing of the task acronyms. Coordinate points for each task are listed as $x, y$, and $z$. The fourth value listed is the maximal $t$ value. A negative $x$ coordinate value denotes a left hemisphere foci; a positive coordinate value denotes a right hemisphere foci. Shaded $t$ values indicate a decrease rather than an increase from the baseline condition.

compared with impossible objects during ORN-BL $(P<0.05)$ and in the region of the right and left hippocampus during ORN-NRN $(P<0.05)$; and (3) the blood flow increase was significantly

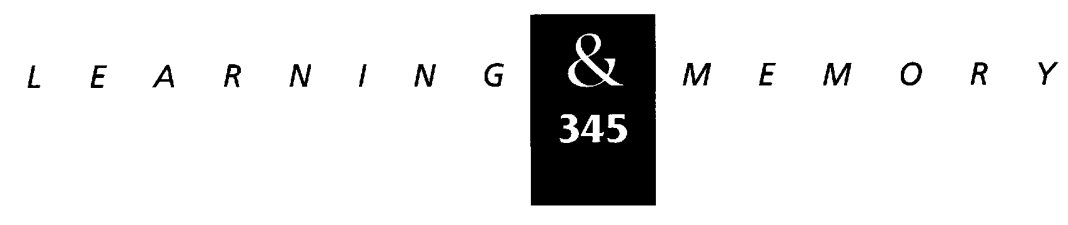


Uecker et al.

greater in the region of the left hippocampus for impossible as compared to possible objects during ORN-BL and NOD-BL (both $P<0.005$ ) and NRNBL and NOD-BL (both $P<0.05$ ). Blood flow increases in the hippocampus region are illustrated in Figure 3.

The hippocampus and parahippocampal gyrus occupy seven Talairach and Tournoux (1988) planes. The increases we observed during object decision and recognition memory appeared to occupy only the four dorsal transaxial sections. To test this hypothesis, we extracted the raw PET counts from the hippocampal and parahippocampal regions in Talairach space. Post-hoc analyses of these data confirmed the impression of a greater increase in the region of the dorsal hippocampus and parahippocampal gyrus (Talairach z-levels $=4,0,-4$, and -8 ) than in the ventral hippocampus and parahippocampal regions (Talairach z-levels $=-12,-16$, and -20$), F(1,15)=5.39$, $P<0.001$. Although a main effect of region (dorsal hippocampus vs. dorsal parahippocampal gyrus) was lacking, there was a significant interaction of region $\mathrm{x}$ object type (possible, impossible), $F(1,15)=11.31, P<0.005$ : parahippocampal activity was associated with possible objects and hippocampus activity was associated with impossible objects. In addition, a significant region $\mathrm{x}$ task (ob-

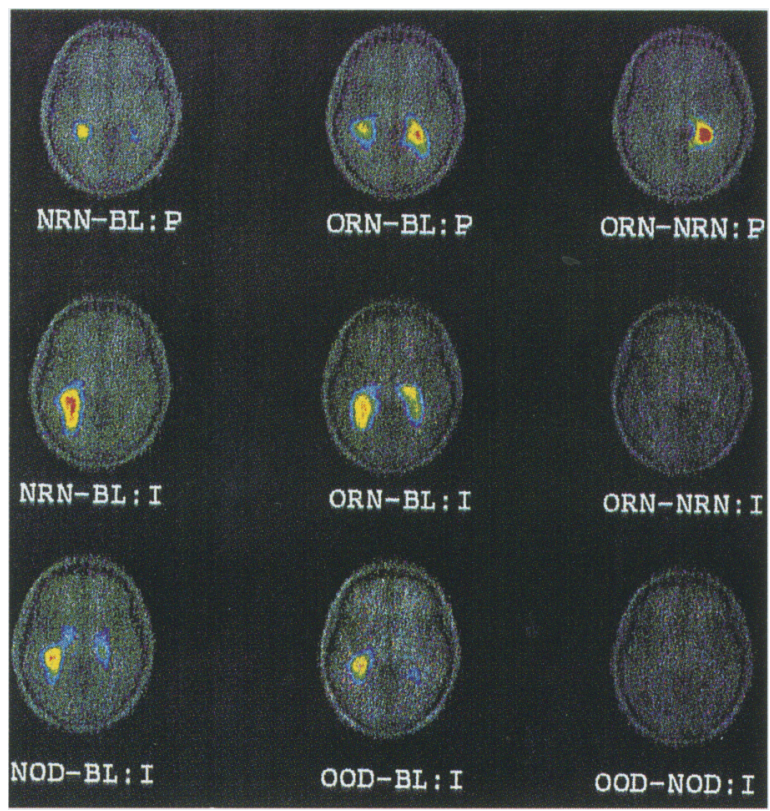

Figure 3: Blood flow increases in the hippocampus region during object decision and recognition memory. Refer to Table 1 for a definition of the task acronyms. ject decision, recognition memory) interaction, $F(1,15)=10.08, P<0.01$, indicated that although the hippocampus showed greater increases than the parahippocampal gyrus during object decision, the reverse was true for recognition memory. The last significant interaction is region $\mathrm{x}$ hemisphere, $F(1,15)=8.08, P<0.05$. Blood flow is greater in the left hippocampus than in the left parahippocampal gyrus, and blood flow is less in the right hippocampus than in the right parahippocampal gyrus.

The region of interest approach that used each subject's MRI as an aid in the definition of the hippocampus also confirmed the impression of a greater blood flow increase in the region of the dorsal hippocampus as compared with the ventral hippocampus, $F(1,18)=17.64, P<0.005$. In addition, and considering all of the memory tasks together, the blood flow increase was significantly greater in the left hippocampus than in the right hippocampus, $F(1,14)=6.91, P<0.05$. In contrast to the Talairach extraction technique, however, further distinctions could not be made on the basis of either task or object type.

\section{FRONTAL LOBE}

Blood flow increases occurred in the precentral (somatosensory, motor, and supplementary motor areas), dorsolateral prefrontal (DLPFC) and orbitofrontal cortices in all of the object decision and recognition memory tasks as compared to the no-decision baseline condition. Blood flow increases in the precentral cortex occurred ubiquitously on the left, but were bilateral in NOD-BL:I. Blood flow increases in the prefrontal area (here defined as BA 10, 44-46) are all bilateral with two exceptions. Blood flow was significantly greater in the right hemisphere during NRN-BL:P, and in the left hemisphere during ORN-NRN:P. Blood flow increases in the orbitofrontal cortex (BA 11 and 47) are also primarily bilateral. The exception, OOD-BL:P, has blood flow increases on the right side only.

In comparison with the no-decision baseline condition, a trend for increased blood flow in the frontal eye field region (BA8) is present during NOD:P and ORN:P. In contrast, a trend for a decrease in this region is present during OOD:P, NOD:I, ORN:I, NRN:P, and NRN:I. Both trends for and significant decreased blood flow occur in the midline central sulcus region in BA9. This area of

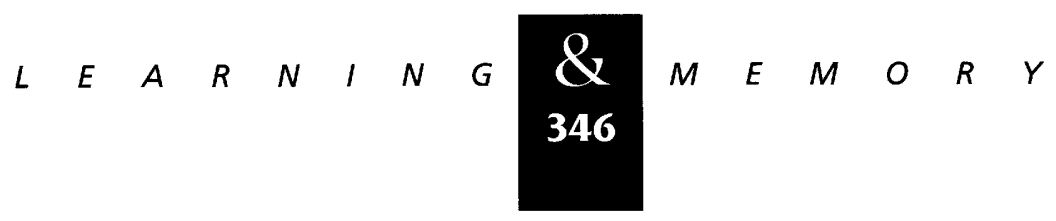


decrease often included anterior cingulate region BA 32.

\section{THALAMUS}

Blood flow increases in the thalamus occurred predominantly in its posterior sector, the pulvinar, during ORN-BL:I, NRN-BL:P, NRN-BL:I, OODBL:I, and NOD-BL:I. There was no pulvinar increase in OOD-BL:P. Post-hoc analyses of the PET counts extracted from the anterior and the posterior thalamus in Talairach and Tournoux (1988) space confirmed the SPM implication of greater pulvinar activation, $F(1,15)=4.94, P<0.05$. Although there was no difference in thalamic increases between either the hemispheres or object types, the increase in the pulvinar region was significantly greater during recognition memory as compared to object decision $F(1,15)=$ 13.01, $P<0.005$.

OCCIPITAL CORTEX

Object and recognition decisions were each distinguished from their respective no-decision baseline tasks by significantly increased CBF in the vicinity of the medial occipital cortex (BAs 17-19). Recognition decisions about previously studied possible objects were distinguished from those about previously nonstudied conditions by significantly decreased CBF bilaterally in the vicinity of medial and lateral occipital cortex (BAs 17-19).

\section{THE CINGULATE GYRUS}

Blood flow increases in the vicinity of the posterior and mid-cingulate cortex (BAs 23 and 24, respectively) occurred during each recognition memory task in comparison with the no-decision baseline condition, and in ORN:P as contrasted with NRN:P. Significant blood flow decreases in anterior cingulate $\mathrm{BA} 32$ occurred in conjunction with those in the midline frontal region (BA9) during OOD-BL:P, OOD-BL:I, NOD-BL:P, and ORNBL:I.

\section{LENTIFORM NUCLEUS AND CAUDATE}

Bilateral blood flow increases occurred in the vicinity of the lentiform nucleus during ORN-BL:P and ORN-BL:I. A bilateral blood flow decrease in this same region occurred during NOD-BL:I. Significant blood flow increases in the caudate during object decision were bilateral in OOD-BL:I, on the right in OOD-BL:P, and on the left in NOD-BL:I. In recognition memory, significant bilateral blood flow increases occurred in the caudate in association with ORN-BL:P, ORN-BL:I, and NRN-BL:I, as well as in ORN:P in contrast to NRN:P.

\section{INSULAR REGION}

Significant bilateral blood flow increases occurred in all of the object decision and recognition memory tasks when compared with the no-decision baseline condition with two exceptions. In NRN-BL:P, significant increases occurred only in the right hemisphere, and in OOD-BL:I significant increases occurred only in the left hemisphere.

PRECUNEUS

Significant bilateral blood flow decreases in the vicinity of the precuneus, superior parietal cortex (BA7) and posterior cingulate region (BA31) occurred in all of the object decision and recognition memory tasks as compared to the no-decision baseline condition. Often included in this region were the primary and secondary visual cortices, as well as the other posterior cingulate regions.

TEMPOROPARIETAL REGIONS

Significant blood flow decreases in the inferior parietal cortex and the middle and superior temporal gyri occurred in all of the object decision and recognition memory tasks when compared with the no-decision baseline condition, and in ORN:P as contrasted with NRN:P. Significant increases also occurred in the superior angular and supramarginal gyri bilaterally during OOD-BL:P, on the left in OOD-BL:I, and on the right in NOD-BL:P.

\section{CEREBELLUM}

Bilateral blood flow decreases in the cerebellum occurred in association with all of the object decision and recognition memory tasks, when compared with the no-decision baseline condition.

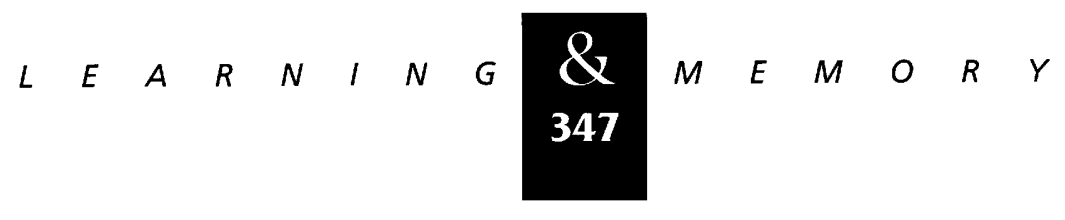




\section{Discussion}

Like subjects in previous cognitive studies, subjects in this PET study demonstrated object decision priming for previously studied possible but not impossible objects, recognition memory for previously studied possible and impossible objects, and reliably greater recognition memory for possible than for impossible objects. This study confirmed hypotheses that object decision priming depends on a neural system that includes a brain structure in the vicinity of the inferior temporal cortex, that the inferior temporal cortex participates in the global representation of visual objects (a representation preferentially involved in decisions about objects that are structurally possible), and that explicit memory for visual objects depends on a brain structure in the vicinity of the hippocampus. Additional data analyses into task, object, and hemisphere effects provide insight into the neuroanatomy of the encoding and retrieval operations involved in the implicit and explicit recognition of visual objects. CBF increases and decreases in brain regions outside of the inferior temporal gyrus and hippocampus regions provide additional information about brain structures participating in the implicit and explicit retrieval of visual information.

\section{INFERIOR TEMPORAL REGIONS, OBJECT DECISION,} AND OBJECT DECISION PRIMING

Significant increases in the inferior temporal (IT) and fusiform gyri regions occurred only during object decision and only for possible objects. Increased blood flow was in the right hemisphere during NOD-BL:P, bilateral during OOD-BL:P, and in the left hemisphere during OOD-NOD:P. Both the right hemisphere increase in NOD-BL:P and the left hemisphere increase in OOD-NOD:P were significantly greater than in the opposite hemisphere. In addition, the increases appearing in the inferior temporal and fusiform region in association with possible objects were significantly greater than those for impossible objects.

Priming of verbal stimuli has been examined in several previous functional neuroimaging studies (Squire et al. 1992; Buckner et al. 1995). Squire et al. (1992) initially reported decreased blood flow in the right posterior cortex in a word-stem completion priming task, whereas in a subsequent analysis Buckner and colleagues (1995) reported bilateral decreases. Schacter et al. (1996b) also found bilateral occipital decreases in relation to priming. Decreases in this region might be attributable to more efficient processing of a stimulus after an initial exposure to a target word on the study list.

Decreased neuronal responsiveness in the inferior temporal cortex (IT) in response to stimulus repetition has also been linked to memory (Li et al. 1993; Miller et al. 1991, 1993; Miller and Desimone 1994). Desimone and colleagues (1995) currently speculate on the presence of two to three memory processes within IT cortex. The first, based on simple stimulus repetition, is characterized by attenuated neural responsiveness. This may be the type of mechanism observed in the previous PET studies with verbal materials (Squire 1992; Buckner et al. 1995). The other two memory mechanisms are associated with neuronal enhancement and active maintenance of a stimulus, respectively, and they are hypothesized to depend in part on top-down feedback from prefrontal regions to IT cortex. Prominent increases in the prefrontal cortex were observed in the present study; functional interaction between the prefrontal and inferior temporal cortex during object decision, therefore, could account, in part, for the increase that we obtained in association with priming.

A last note regards the laterality of our findings. Hemispheric functions in the right and left temporal areas have often been related to nonverbal and verbal abilities, respectively. Blood flow increases in the right inferior temporal region in response to nonstudied possible objects implicate the involvement of this region in the incorporation of unfamiliar information. The right temporal lobe has been implicated previously in "rapid visual identification" (Milner 1958) that is dependent on the degree of familiarity with the material (Kimura 1963). Blood flow increases in the right occipitotemporal region have also been demonstrated for other three-dimensional novel objects (Kanwisher et al. 1994). Blood flow increases in the left inferior temporal region in response to making decisions about possible objects, by contrast, suggest this region's involvement in the incorporation of familiar information. Increased blood flow in left BA21 has been demonstrated during previous studies of face and object identification (Corbetta et al. 1990; Sergent et al. 1992; Kosslyn et al. 1994). It has been argued that this portion of cortex is important in the naming but not the recognition, of visual objects (Damasio 1990; Damasio et al. 1990).

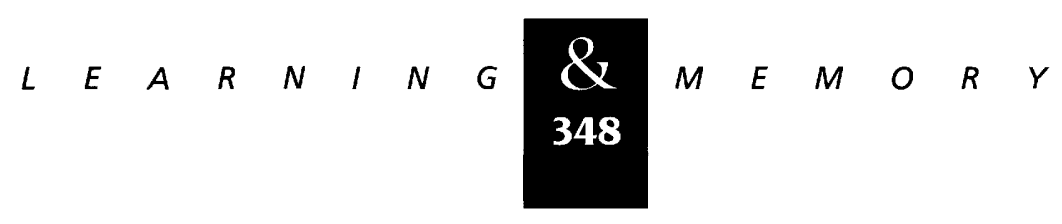


HIPPOCAMPAL REGIONS, OBJECT

AND RECOGNITION DECISIONS, AND RECOGNITION MEMORY

Blood flow increases in the hippocampus occurred in association with both recognition memory and object decision. As in the inferior temporal cortex, the pattern of increases in the two hemispheres appears to reflect information about object familiarity. Blood flow increases occurred in the region of the left hippocampus during NRN$B L: P$, bilaterally during ORN-BL:P, and in the region of the right hippocampus during ORNNRN:P. Blood flow increases in the left hippocampus region occurred in response to impossible objects, irrespective of task. In contrast to the increases in the inferior temporal region, the response to familiar (studied) objects was in the right hemisphere, and the response to nonfamiliar objects was in the left hemisphere. This pattern of lateralized increases possibly reflects a distinction between analysis and encoding functions in the left hippocampus and a perceptual matching function in the right hippocampus.

In agreement with recent primate work (Meunier et al. 1993; Suzuki et al. 1993), the results of the present study indicate that it is the parahippocampal region (and not the hippocampus proper) that demonstrates significantly greater increases during recognition memory. Parahippocampal increases are notably less in the left hemisphere and in response to impossible objects.

Right hippocampus increases during word stem completion led Squire and colleagues (1992) to assert a clear association between increased blood flow in the hippocampus and memory. During this task, subjects completed word stems with words previously studied. In a subsequent study, however, Buckner et al. (1995) demonstrated that if the format of the study words differed from that of the test words, there was no increase in the hippocampus, despite equivalent memory performance, suggesting that the response of the right hippocampus is specific to matching stimuli (cf. Schacter 1997b). Schacter et al. (1996a) have shown that right hippocampus increases during stem-cued recall are observed under conditions that promote high levels of recall, but not under conditions that yield low levels of recall. This finding parallels the present observation of right parahippocampal activation in association with explicit recognition of possible but not impossible objects. Other recent studies, too, have shown activation of the hippocampal region under conditions that promote successful conscious recollection of recently studied pictures (Gabrieli et al. 1997), words (Nyberg et al. 1996b; Rugg et al. 1997), and objects in particular spatial positions (Owen et al. 1996).

Tulving and colleagues (1994c) suggest that the right hippocampus may be a component of a novelty encoding network (cf. Stern et al. 1996; Gabrieli et al. 1997). In their experiment, increases in the right hippocampus region occurred during exposure to nonstudied National Geographic illustrations. Although these pictures were novel in the sense that they had not been seen before in the experimental setting, they contain familiar everyday objects and therefore are not novel in the same sense that our objects are novel. We suggest two alternative interpretations. First, the increases observed by Tulving et al. (1994c) could reflect a holistic matching function to familiar real world stimuli; substantial analysis of these stimuli is unnecessary. Second, the increases may be similar to those that occurred in the right inferior temporal region in response to possible objects during object decision. Neuroimaging studies are needed to differentiate the role of the left and right hippocampi in encoding and retrieval functions.

A last note about the increases in the hippocampus concerns their location in the transaxial plane of section. Visual inspection, extraction of the PET counts in Talairach space, and extraction of PET counts from the hippocampus region of each subject's individual MRI image all confirmed that the increases observed in this study were consistently found in the dorsal hippocampus region. Inputs to the dorsal and ventral regions of the hippocampus are from separate areas of the entorhinal cortex in rats (Wyss 1981), cats (Witter and Groenewegen 1984), monkeys (Suzuki and Amaral 1994b), and presumably in humans. It has been suggested that these two hippocampal regions subserve different functions. For example, in the monkey, input to the dorsal hippocampal region tends to be from the rostromedial entorhinal cortex and input to the ventral hippocampal region tends to be from the more caudal extent of the entorhinal cortex (Witter et al. 1989). Input to the rostromedial entorhinal cortex originates from perirhinal cortex, a strong recipient of "what" or object-based information from unimodal visual areas in the temporal lobe, whereas input to the caudal entorhinal cortex region originates from the parahippocampus cortex, a strong recipient of "where" or location-based

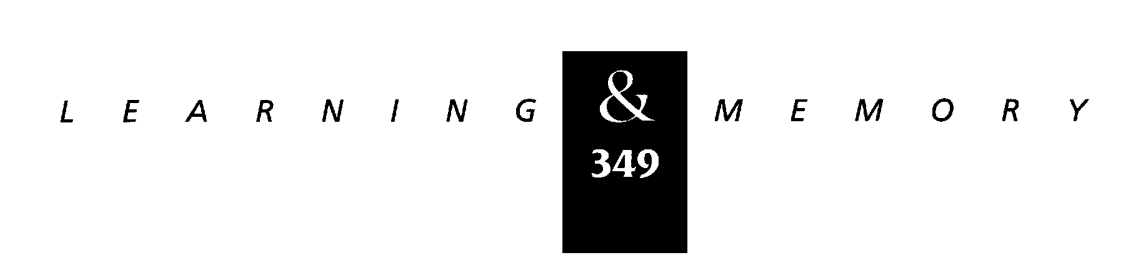


information from such areas as the retrosplenial cortex and posterior parietal cortex (Suzuki and Amaral 1994a,b), two areas that showed decreases in the present study. Our data indicate that possible and impossible object information processing occurs preferentially in the visual stream that processes what information important for visual recognition and memory.

\section{METHODOLOGICAL LIMITATIONS}

A major criticism of brain images acquired with PET is their inability to accurately localize blood flow changes due to limitations of present anatomical standardization techniques and spatial resolution. Despite these limitations, we have used Talairach space to define human neuroanatomy and to claim that we can differentiate blood flow increases in the parahippocampal gyrus region from blood flow increases in the hippocampus. Additionally, we have defined the hippocampal formation on each subject's MRI and coregistered these images to each of the subject's respective PET images and made the claim that blood flow increases in the dorsal hippocampus can be differentiated from blood flow increases in the ventral hippocampus. Our claim, therefore, is limited by the methods we used to extract area-specific raw PET data. We acknowledge that neuroanatomical imprecision can be attributable to several sources - the resolution of the PET images, the inexactness of Talairach space, and inaccuracies in the coregistration procedure. Although anatomical data gathered in primates supports the plausibility of our exploratory analyses, within-subject image averaging and functional MRI (fMRI) are better suited to providing a more definitive conclusion.

\section{CBF INCREASES IN THE OTHER BRAIN REGIONS}

In comparison with the no-decision baseline task, the object decision and recognition memory tasks were associated with blood flow increases bilaterally in the vicinity of the dorsolateral prefrontal cortex, bilaterally in the vicinity of the orbitofrontal cortex, bilaterally in the insular cortex, in the left hemisphere somatosensory, motor and supplementary motor areas, and either bilaterally or in the right hemisphere of the posterior nucleus of the thalamus, the pulvinar. Blood flow increases in the pulvinar were greater than those in the an- terior thalamus during the recognition memory tasks. In comparison with the no-decision baseline task, the recognition memory tasks were associated with blood flow increases bilaterally in the anterior cingulate cortex region and bilaterally in the region of the caudate nucleus. In comparison with the no-decision baseline task, the object decision tasks were associated with blood flow increases in parietal cortex regions 39 and 40.

The dorsolateral prefrontal cortex is thought to be involved in working memory (Goldman-Rakic 1987,1988 ), a supervisory attentional system (Shallice 1982), behavioral programming (Nauta 1971), and other executive functions such as the inhibition of inappropriate behavioral responses (Mesulam 1985). That this region has a role in explicit memory has been demonstrated in several previous PET studies (Squire et al. 1992; Grasby et al. 1993; Petrides et al. 1993a,b; Kapur et al. 1994; Swartz et al. 1994; Tulving et al. 1994a,b; Buckner et al. 1995; Schacter et al. 1997a). Blood flow increases in the orbitofrontal region, in contrast, have been reported to occur in response to certain face and object identification tasks (Sergent et al. 1992), as well as to selective attention to changes in a single visual feature of a form (Corbetta et al. 1991) and may participate in processing information about a visual object's identity. PET activity in the insula has been demonstrated in response selection tasks that are based on simple or limited processing of input to overlearned or automatic task performance (Corbetta et al. 1991; Raichle et al. 1994). Activity in the somatosensory, motor, and supplementary motor areas usually occur in tasks that involve a motor component. In our study, however, motor responses (a right or a left button press) should have been accounted for in the active no-decision baseline condition and therefore cannot be the source of the observed increases. Activity in this region, therefore, could reflect additional coordination of sensory and motor information not required during the baseline condition.

Although the functional role of the pulvinar is not entirely clear, suggestions from previous PET studies include retrieval of images from memory (Roland et al. 1987), the analysis of a visual representation with a specific hypothesis in mind (Roland and Gulyas 1995), selective vigilance (Corbetta et al. 1991), and the identification of a particular stimulus in a cluttered field (LaBerge and Buchsbaum 1990). LaBerge and Brown (1989) speculate that the pulvinar acts as a filter engaged

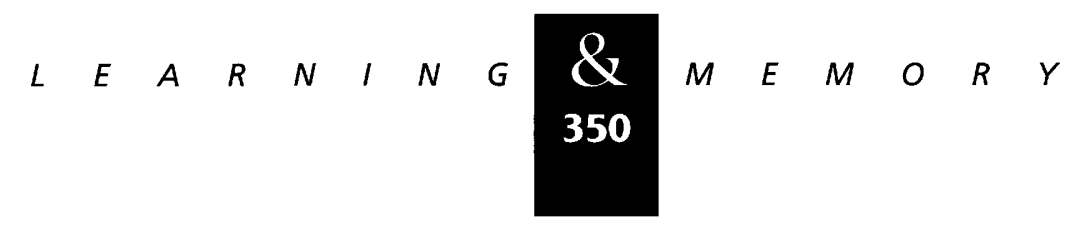


to amplify specific attended stimulus features. With our complex geometric visual stimuli, the pulvinar may be acting to highlight conjunctive features for the purpose of building a structural visual description (e.g., Olshausen et al. 1993).

The anterior cingulate region participates in selection for action (Pardo et al. 1990; Grasby et al. 1993; Raichle et al. 1994) among competing, complex contingencies (Posner et al. 1988; Posner and Petersen 1990). Blood flow increases that occur in response to the demands of recognition memory are consistent with the importance of the anterior cingulate in the conscious manipulation of attention. Corbetta and colleagues (1991) speculate that a circuit between the orbitofrontal cortex and structures in the basal ganglia act to adopt and maintain a set in short term memory for a particular feature. Similar information processing loops with the dorsolateral prefrontal cortex and the anterior cingulate have been proposed by Alexander and colleagues (Alexander et al. 1986). Except for their acknowledged role in procedural learning, the functional role of striato-pallido-thalamic-cortical circuits in cognition has not delineated well.

The increases in the parietal cortex were observed only in the most superior regions of the brain. Increases in the right inferior parietal region have been demonstrated previously in response to objects viewed from a noncanonical perspective (Kosslyn et al. 1994). Increases in this region in response to possible and impossible objects may be related to visual manipulation of these objects during object decision. The role of the inferior parietal region in persisting Wernicke's aphasia (Kertesz et al. 1993) further suggests an attempt to extract meaning or to understand and more fully encode the stimuli.

\section{CBF DECREASES IN THE OTHER BRAIN REGIONS}

In comparison to the no-decision baseline task, the object decision and recognition memory tasks were associated with blood flow decreases bilaterally in the primary and secondary visual regions, BAs 17-19, in the precuneus region, in the inferior parietal cortex and the middle and superior temporal gyri, and in the cerebellum.

Blood flow decreases in primary visual cortex (BA17) have been demonstrated previously during the viewing of visual objects (Schacter et al. 1996b)-despite the fact that these subjects had only heard the names of the objects initially. $\mathrm{Ny}$ - berg and colleagues (1996a) suggest that neural activity from the higher level associative regions actively inhibit regions not directly involved in immediate information processing demands (see also, Kawashima et al. 1993).

Increases rather than decreases have been reported more often in the precuneus region (Roland and Seitz 1989; Grasby et al. 1993, 1994; Gulyas et al. 1994; Shallice et al. 1994; Roland and Gulyas 1995). Corbetta and colleagues were able to dissociate precuneus increases from decreases by manipulating attention-when attention was directed peripherally, increases in blood flow were observed; in contrast, when attention was directed to the center of a visual display, hypoperfusion resulted. The cognitive operations involved in this experiment, as well the lack of peripherally directed attention, may have precluded the involvement of the precuneus, a region that appears to be involved in the active analysis of spatial information (Murray et al. 1989; Haxby et al. 1991; Vogt et al. 1992).

The cerebellum, in contrast, is putatively involved in shifts of attention (Akshoomoff and Courchesne 1992), as well the ability to respond to motor requirements of the task with increasing automaticity (e.g., Fiez et al. 1992; Grasby et al. 1994; Raichle et al. 1994). Cerebellum participation may be required only for initial motor programming.

\section{SUMMARY}

Blood flow increases in the inferior temporal and fusiform gyri during object decisions about possible visual objects and object decision priming provide support for the role of this region in representing and maintaining structural descriptions of objects. Additionally, blood flow increases in the right hippocampus during explicit recognition for possible visual objects provide support that this region has a role in recognizing familiar or matching visual stimuli. Blood flow increases in the left hippocampus that occur in response to nonstudied possible objects and to impossible objects suggest that this brain region is involved in stimulus encoding and feature analysis. Blood flow increases in the posterior (pulvinar) but not anterior thalamic region highlight this structure's contribution to the visual analysis of complex visual objects. Blood flow increases and decreases in these and other regions provide information about the role of specific as well as spatially distributed (network) brain

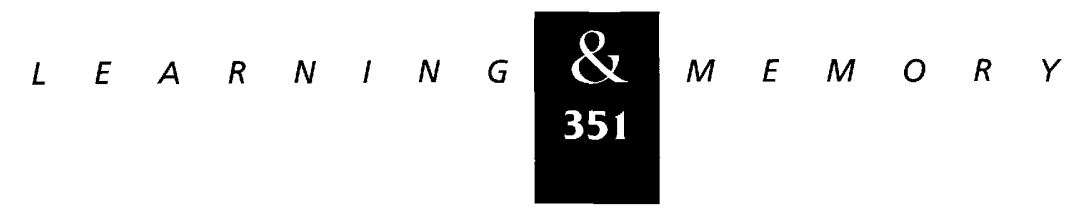


processes and related mental operations underlying performance on implicit and explicit tests of memory for novel visual objects.

\section{Acknowledgments}

We thank A. Randall Mclntosh for providing a matlab program; Dan Bandy, Nissa Blocher, Alan Evans, Deanna Guerra, Mark Mintun, Kim Nelson, and Karen Zemanick for technical assistance; and Bruce McNaughton and Carol Barnes for resource support. This work was supported by grants from the McDonnell-Pew Program in Cognitive Neuroscience, the Robert S. Flinn Foundation, and the National Institute for Mental Health (NIMH).

\section{References}

Akshoomoff, N.A. and E. Courchesne. 1992. A new role for the cerebellum in cognitive operations. Behav. Neurosci. 106: $731-738$.

Alexander, G.E., M.R. DeLong, and P.L. Strick. 1986. Parallel organization of functionally segregated circuits linking basal ganglia and cortex. Ann. Rev. Neurosci. 9: 357-381.

Buckner, R.L., S.E. Petersen, J.G. Ojemann, F.M. Miezin, L.R. Squire, and M.E. Raichle. 1995. Functional anatomical studies of explicit and implicit memory retrieval tasks. J. Neurosci. 15: 12-20.

Cooper, L.A., D.L. Schacter, S. Ballesteros, and C. Moore. 1992. Priming and recognition of transformed three-dimensional objects: Effects of size and reflection. J. Exp. Psychol.: Learning, Mem., and Cognition 18: 43-57.

Corbetta, M., F.M. Miezin, S. Dobmeyer, G.L. Shulman, and S.E. Petersen. 1990. Attentional modulation of neural processing of shape, color, and velocity in humans. Science 248: 1556-1559.

1991. Selective and divided attention during visual discrimination of shape, color, and speed: Functional anatomy by positron emission tomography. J. Neurosci. 11: 2383-2402.

Damasio, A.R. 1990. Category-related recognition defects as a clue to the neural substrates of knowledge. Trends Neurosci. 13: 95-98.

Damasio, A.R., H. Damasio, D. Tranel, and J.P. Brandt. 1990. Neural regionalization of knowledge access: Preliminary evidence. Cold Spring Harb. Symp. Quant. Biol. 54: 1039-1047.

Desimone, R. and J. Duncan. 1995. Neural mechanisms of selective visual attention. Ann. Rev. Neurosci. 18: 193-222.

Fiez, J., S.E. Petersen, M.K. Cheney, and M.E. Raichle. 1992. Impaired nonmotor learning and error detection associated with cerebellar damage. Brain 115: 155-178.

Friston, K.J., C.D. Frith, P.F. Liddle, R.J. Dolan, A.A.
Lammertsma, and R.S.J. Frackowiak. 1991. Comparing functional (PET) images: The assessment of functional change. J. Cerebr. Blood Flow Metab. 11: 690-699.

Gabrieli, J.D.E., J.B. Brewer, J.E. Desmond, and G.H. Glover. 1997. Separate neural bases of two fundamental memory processes in the human medial temporal lobe. Science 276: $264-266$.

Goldman-Rakic, P.S. 1987. Circuitry of primate prefrontal cortex and regulation of behavior by representational memory. In Handbook of Physiology: The nervous system (ed. F. Plum and V. Mountcastle), pp. 373-417. American Physiology Society, Bethesda, MD.

Goldman-Rakic, P.S. 1988. Topography of cognition: Parallel distributed networks in primate association cortex. Ann. Rev. Neurosci. 11: 137-156.

Graf, P. and M.E.J. Masson. 1993. Implicit memory: New directions in cognition, development, and neuropsychology. Lawrence Erlbaum Associates, Hillsdale, NJ.

Graf, P. and D.L. Schacter. 1985. Implicit and explicit memory for new associations in normal and amnesic subjects. J. Exp. Psychol.: Learning, Mem., and Cognition 11: $501-518$.

Grasby, P.M., C.D. Frith, K.J. Friston, C. Bench, R.S.J. Frackowiak, and R.J. Dolan. 1993. Functional mapping of brain areas implicated in auditory-verbal memory function. Brain 116: 1-20.

Grasby, P.M., C.D. Frith, K.J. Friston, J. Simpson, P.C. Fletcher, R.S.J. Frackowiak, and R.J. Dolan. 1994. A graded task approach to the functional mapping of brain areas implicated in auditory-verbal memory. Brain 117: 1271-1282.

Gulyas, B., C.A. Heywood, D.A. Popplewell, P.E. Roland, and A. Cowey. 1994. Visual form discrimination from color or motion cues: Functional anatomy by positron emission tomography. Proc. Natl. Acad. Sci. 91: 9965-9969.

Haxby, J.V., C.L. Grady, B. Horwitz, L.G. Ungerleider, M. Mishkin, R.E. Carson, P. Herscovitch, and M.B. Shapiro. 1991. Dissociation of object and spatial vision processing pathways in human extrastriate cortex. Proc. Natl. Acad. Sci. 88: 1621-1625.

Kanwisher, N., R. Woods, J. Mazziotta, and M. lacoboni. 1994. PET studies of object recognition. Soc. Neurosci. Abstr. 20: 840 .

Kapur, S., F.I.M. Craik, E. Tulving, A.A. Wilson, S. Houle, and G.M. Brown. 1994. Neuroanatomical correlates of encoding in episodic memory: Levels of processing effect. Proc. Natl. Acad. Sci. 91: 2008-2011.

Kawashima, R., B.T. O'Sullivan, and P.E. Roland. 1993. A PET study of selective attention in man: Cross-modality decreases in somatosensory and visual tasks. J. Cerebr. Blood Flow and Metab. 13: S502.

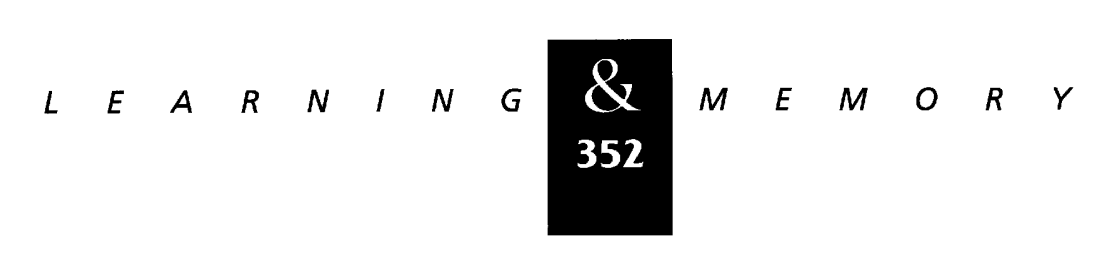


Kertesz, A., W.K. Lau, and M. Polk. 1993. The structural determinants of recovery in Wernicke's aphasia. Brain Lang. 44: 153-164.

Kimura, D. 1963. Right temporal-lobe damage. Arch. Neurol. 8: 264-271.

Kosslyn, S.M., N.M. Alpert, W.L. Thompson, C.F. Chabris, S.L. Rauch, and A.K. Anderson. 1994. Identifying objects seen from different viewpoints: A PET investigation. Brain 117: 1055-1071.

LaBerge, D. and M.S. Buchsbaum. 1990. Positron emission tomographic measurements of pulvinar activity during an attention task. J. Neurosci. 10:613-619.

LaBerge, D. and V. Brown. 1989. Theory of attentional operations in shape identification. Psychol. Rev.

96: $101-124$

Li, L., E.K. Miller, and R. Desimone. 1993. The representation of stimulus familiarity in anterior inferior temporal cortex. $J$. Neurophysiol. 69: 1918-1929.

Mesulam, M.-M. 1985. Principles of Behavioral Neurology. F.A. Davis, Philadelphia, PA.

Meunier, M., J. Bachavalier, M. Mishkin, and E.A. Murray. 1993. Effects on visual recognition of combined and separate ablations of the entorhinal and perirhinal cortex in rhesus monkeys. J. Neurosci. 13: 5418-5432.

Miller, E.K. and R. Desimone. 1994. Parallel neuronal mechanisms for short-term memory. Science 28: 520-522.

Miller, E.K., L. Li, and R. Desimone. 1991. A neural mechanism for working and recognition memory in inferior temporal cortex. Science 29: 1377-1379.

1993. Activity of neurons in anterior inferior temporal cortex during a short term memory task. J. Neurosci. 13: 1460-1478.

Milner, B. 1958. Psychological defects produced by temporal lobe excision. Res. Publ. Ass. Res. Nerv. Ment. Dis. 36: $244-257$.

Mintun, M.A. and K.S. Lee. 1991. J. Nuclear Med. 31: 816.

Moscovitch, M. 1994. Memory and working with memory: Evaluation of a component process model and comparisons with other models. In Memory Systems 1994 (ed. D.L. Schacter and E. Tulving), MIT Press, Cambridge, MA.

Murray, E.A., M. Davidson, D. Gaffan, D.S. Olton, and S. Suomi. 1989. Effects of fornix transection and cingulate cortical ablation on spatial memory in rhesus monkeys. Exp. Brain Res. 74: 173-186.

Nauta, W.J.H. 1971. The problem of the frontal lobe: A reinterpretation. J. Psychiatr. Res. 8: 167-187.

Nyberg, L., A.R. Mcintosh, R. Cabeza, L.-G. Nilsson, S.
Houle, R. Habib, and E. Tulving. 1996a. Network analysis of PET rCBF data: Ensemble inhibition during episodic memory retrieval. J. Neurosci. 16: 3753-3759.

Nyberg, L., A.R. McIntosh, S. Houle, L.-G. Nilsson, and E. Tulving. 1996b. Activation of medial temporal structures during episodic memory retrieval. Nature 380: 715-717.

Olshausen, B.A., C.H. Anderson, and D.C. Van Essen. 1993. A neurobiological model of visual attention and invariant pattern recognition based on dynamic routing of information. J. Neurosci. 13: 4700-4719.

Owen, A.M., B. Milner, M. Petrides, and A.C. Evans. 1996. A specific role for the right parahippocampal gyrus in the retrieval of object location: A positron emission tomography study. J. Cognitive Neurosci. 8: 588-602.

Pardo, J.V., P.J. Pardo, K.W. Janer, and M.E. Raichle. 1990. The anterior cingulate cortex mediates processing selection in the Stroop attentional conflict paradigm. Proc. Natl. Acad. Sci. 87: 256-259.

Petrides, M., B. Alivisatos, A.C. Evans, and E. Meyer. 1993a. Dissociation of human mid-dorsolateral from posterior dorsolateral frontal cortex in memory processing. Proc. Natl. Acad. Sci. 90: 873-877.

Petrides, M., B. Alivisatos, E. Meyer, and A.C. Evans. 1993b. Functional activation of the human frontal cortex during the performance of verbal working memory tasks. Proc. Natl. Acad. Sci. 90: 878-882.

Posner, M.I., S.E. Petersen, P.T. Fox, and M.E. Raichle. 1988 Localization of cognitive operations in the human brain. Science 240: 1627-1631.

Posner, M.L. and S.E.A. Petersen. 1990. The attention system of the human brain. Ann. Rev. Neurosci. 13: 25-42.

Raichle, M.E., J.A. Fiez, T.O. Videen, A.-M.K. MacLeod, J.V. Pardo, P.T. Fox, and S.E. Petersen. 1994. Practice-related changes in human functional anatomy during nonmotor learning. Cerebr. Cortex 4: 8-26.

Reiman, E.M., R.D. Lane, G.L. Ahern, G.E. Schwartz, R.J. Davidson, K.J. Friston, L.-S. Yun, and K. Chen. 1997. Neuroanatomical correlates of externally and internally generated human emotion. Am. J. Psychiatry 154: 918-925.

Richardson-Klavehn, A. and R.A. Bjork. 1988. Measures of memory. Ann. Rev. Psychol. 39: 475-543.

Riddoch, M.J. and G.W. Humphreys. 1987. Visual object processing in optic aphasia: A case of semantic access agnosia. Cognitive Neuropsychol. 4: 131-186.

Roediger, H.L. and K.B. McDermott. 1993. Implicit memory in normal human subjects. In Handbook of Neuropsychology (ed. H. Spinnler and F. Boller), Elsevier, Amsterdam, The Netherlands.

Roland, P.E., L. Erikkson, S. Stone-Elander, and L. Widen.

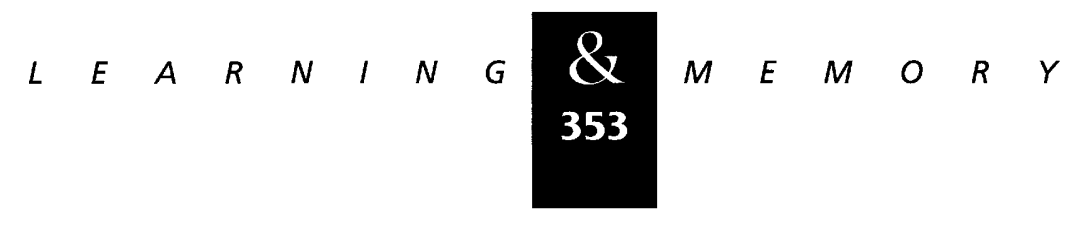


Uecker et al.

1987. Does mental activity change the oxidative metabolism of the brain? J. Neurosci. 7: 2373-2389.

Roland, P.E. and B. Gulyas. 1995. Visual memory, visual imagery, and visual recognition of large field patterns by the human brain: Functional anatomy by positron emission tomography. Cerebr. Cortex 1: 79-93.

Roland, P.E. and R.J. Seitz. 1989. Mapping of learning and memory functions in the human brain. In Visualization of Brain Functions (ed. D. Ottoson and W. Rostene), pp. 141-151. Macmillan, London, UK.

Rugg, M.D., P.C. Fletcher, C.D. Frith, R.S.J. Frackowiak, and R.J. Dolan. 1997. Brain regions supporting intentional and incidental memory: A PET study. NeuroReport 8: 1283-1287.

Schacter, D.L. 1987. Implicit memory: History and current status. J. Exp. Psychol.: Learning, Mem., and Cognition 13: $501-518$.

Schacter, D.L. and L.A. Cooper. 1993. Implicit and explicit memory for novel visual objects: Structure and function. $J$. Exp. Psychol.: Learning, Mem., and Cognition 19: 995-1009.

Schacter, D.L. and E. Tulving. 1994. Memory systems 1994. MIT Press, Cambridge, MA.

Schacter, D.L., L.A. Cooper, and S.M. Delaney. 1990. Implicit memory for unfamiliar objects depends on access to structural descriptions. J. Exp. Psychol.: General 119: 5-24.

Schacter, D.L., L.A. Cooper, S.M. Delaney, M.A. Peterson, and M. Tharan. 1991a. Implicit memory for possible and impossible objects: Constraints on the construction of structural descriptions. J. Exp. Psychol.: Learning, Mem., and Cognition 17: 3-19.

Schacter, D.L., L.A. Cooper, M. Tharan, and A.B. Rubens. $1991 \mathrm{~b}$. Preserved priming of novel objects in patients with memory disorders. J. Cognitive Neurosci. 3: 117-130.

Schacter, D.L., C.-Y.P. Chiu, and K.N. Ochsner. 1993. Implicit memory: A selective review. Ann. Rev. Neurosci. 16: $159-182$

Schacter, D.L., L.A. Cooper, and J. Treadwell. 1993. Preserved priming of novel objects across size transformation in amnesic patients. Psychol. Sci. 4: 331-335.

Schacter, D.L., E. Reiman, A. Uecker, M.R. Polster, L.S. Yun, and L.A. Cooper. 1995. Brain regions associated with retrieval of structurally coherent visual information. Nature 376: $587-590$.

Schacter, D.L., N.M. Alpert, C.R. Savage, S.L. Rauch, and M.S. Albert. 1996a. Conscious recollection and the human hippocampal formation: Evidence from positron emission tomography. Proc. Natl. Acad. Sci. 93: 321-325.

Schacter, D.L., E.M. Reiman, T. Curran, L.S. Yun, D. Bandy, K.B. McDermott, and H.L. Roediger. 1996b.

Neuroanatomical correlates of veridical and illusory recognition memory: Evidence from positron emission tomography. Neuron 2: 191-194.

Schacter, D.L., R.L. Buckner, W. Koutstaal, A. Dale, and B. Rosen. 1997a. Late onset of anterior prefrontal activity during true and false recognition: An event-related fMRI study. Neurolmage (in press).

Schacter, D.L., A. Uecker, E.M. Reiman, L.-S. Yun, D. Bandy, K. Chen, L.A. Cooper, and T. Curran. 1997b. Effects of size and orientation change during hippocampal activation during episodic recognition: A PET study. NeuroReport (in press).

Sergent, J., S. Ohta, and B. Macdonald. 1992. Functional neuroanatomy of face and object processing. Brain 115: $15-36$.

Shallice, T. 1982. Specific impairments of planning. Philos. Trans. R. Soc. London B 298: 199-209.

Shallice, T., P. Fletcher, C.D. Frith, P. Grasby, R.S.J. Frackowiak, and R.J. Dolan. 1994. Brain regions associated with acquisition and retrieval of verbal episodic memory. Nature 368: 633-635.

Squire, L.R. 1992. Declarative and nondeclarative memory: Multiple brain systems supporting learning and memory. J. Cognitive Neurosci. 99: 195-231.

1994. Declarative and nondeclarative memory: Multiple brain systems supporting learning and memory. In Memory Systems 1994. (ed. D.L. Schacter and E. Tulving), MIT Press, Cambridge, MA.

Squire, L.R. and S. Zola-Morgan. 1991. The medial temporal lobe memory system. Science 253: 1380-1386.

Squire, L.R., J.G. Ojemann, F.M. Miezin, S.E. Petersen, T.O. Videen, and M.E. Raichle. 1992. Activation of the hippocampus in normal humans: A functional anatomical study of memory. Proc. Natl. Acad. Sci. 89: 1837-1841.

Stern, C.E., S. Corkin, R.G. Gonzalez, A.R. Guimaraes, J.R. Baker, P.J. Jennings, C.A. Carr, R.M. Sugiura, V. Vedantham, and B.R. Rosen. 1996. The hippocampal formation participates in novel picture encoding: Evidence from functional magnetic resonance imaging. Proc. Natl. Acad. Sci. 93: 8660-8665.

Suzuki, W.A. and D.G. Amaral. 1994a. Perirhinal and parahippocampal cortices of the macaque monkey: Cortical afferents. J. Comp. Neurol. 350: 497-533.

1994b. Topographic organization of the reciprocal connections between the monkey entorhinal cortex and the perirhinal and parahippocampal cortices. J. Neurosci. 14: 1856-1877.

Suzuki, W.A., S. Zola-Morgan, L.R. Squire, and D.G. Amaral. 1993. Lesions of the perirhinal and parahippocampal cortices in the monkey produce long-lasting memory impairments in the visual and tactual modalities. J. Neurosci.

13: $2430-2451$.

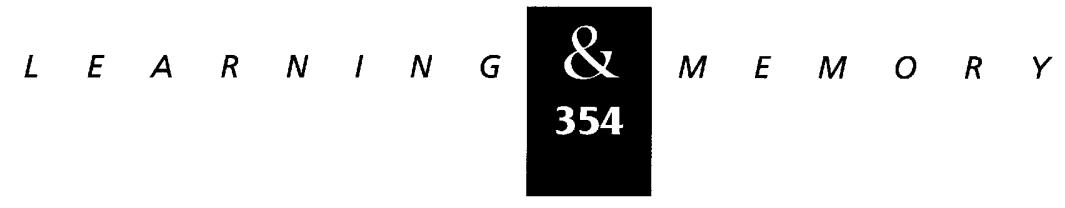


Swartz, B.E., E. Halgren, J. Fuster, and M. Mandelkern. 1994. An 18 FDG-PET study of cortical activation during a short-term visual memory task in humans. NeuroReport 5: 925-928.

Talairach, J. and P. Tournoux. 1988. Co-planar stereotaxic atlas of the human brain. Thieme Medical Publishing, New York, NY.

Tsui, W.H. 1995. Midas (Version 0.6). New York University.

Tulving, E. and D.L. Schacter. 1990. Priming and human memory systems. Science 247: 301-306.

Tulving, E., S. Kapur, F.I.M. Craik, M. Moscovitch, and S. Houle. 1994a. Hemispheric encoding/retrieval asymmetry in episodic memory: positron emission tomography findings. Proc. Natl. Acad. Sci. 91: 2016-2020.

Tulving, E., S. Kapur, H.J. Markowitsch, F.I.M. Craik, R. Habib, and S. Houle. 1994b. Neuroanatomical correlates of retrieval in episodic memory: Auditory sentence recognition. Proc. Natl. Acad. Sci. 91: 2012-2015.

Tulving, E., H.J. Markowitsch, S. Kapur, R. Habib, and S. Houle. 1994c. Novelty encoding networks in the human brain: Positron emission tomography data. NeuroReport 5: 2193-2196.

Vogt, B.A., D.M. Finch, and C.R. Olson. 1992. Functional heterogeneity in cingulate cortex: The anterior executive and posterior evaluative regions. Cerebr. Cortex 2: 435-443.

Willingham, D.B. 1997. Systems of memory in the human brain. Neuron 18: 5-8.

Witter, M.P. and H.J. Groenewegen. 1984. Laminar origin and septotemporal distribution of entorhinal and perirhinal projections to the hippocampus in the cat. /. Comp. Neurol. 224: $371-384$.

Witter, M.P., G.W. VanHoesen, and D.G. Amaral. 1989. Topographical organization of the entorhinal projection to the dentate gyrus of the monkey. J. Neurosci. 9: 216-228.

Wyss, J.M. 1981. An autoradiographic study of the efferent connections of the entorhinal cortex in the rat. J. Comp. Neurol. 199: 495-512.

Received July 7, 1997; accepted in revised form October 7, 1997. 


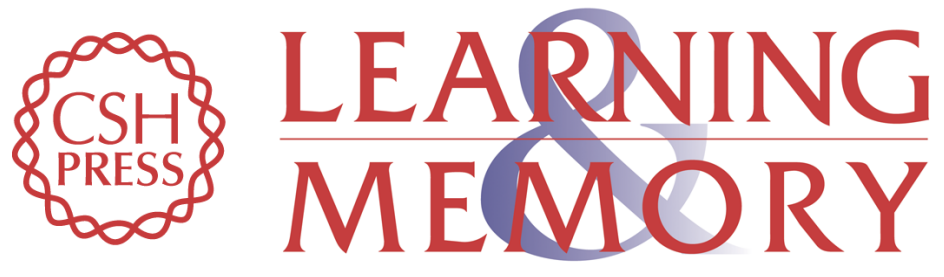

\section{Neuroanatomical correlates of implicit and explicit memory for structurally possible and impossible visual objects.}

A Uecker, E M Reiman, D L Schacter, et al.

Learn. Mem. 1997, 4:

Access the most recent version at doi:10.1101//m.4.4.337

References This article cites 81 articles, 26 of which can be accessed free at: http://learnmem.cshlp.org/content/4/4/337.full.htmI\#ref-list-1

License

Email Alerting Receive free email alerts when new articles cite this article - sign up in the box at the Service top right corner of the article or click here. 